\title{
The failure of success: cyclic recurrences of a globally invasive pest
}

\author{
Zihua Zhao (D) ${ }^{1,9}$ Cang Hui, ${ }^{2,3}$ Richard E. Plant, ${ }^{4}$ Min Su, ${ }^{5}$ Nikos T. Papadopoulos, ${ }^{6}$ Tim E. Carpenter,${ }^{7}$ \\ ZhiHONG Li, ${ }^{1}$ AND JAMES R. CAREY ${ }^{8}$ \\ ${ }^{1}$ Department of Entomology, College of Plant Protection, China Agricultural University, Beijing 100193 China \\ ${ }^{2}$ Department of Mathematical Sciences, Centre for Invasion Biology, Stellenbosch University, Matieland 7602 South Africa \\ ${ }^{3}$ Mathematical and Physical Biosciences, African Institute for Mathematical Sciences, Muizenberg 7945 South Africa \\ ${ }^{4}$ Department of Plant Sciences and Biological and Agricultural Engineering, University of California, Davis, California 95616 USA \\ ${ }^{5}$ School of Mathematics, Hefei University of Technology, Hefei 230009 China \\ ${ }^{6}$ Laboratory of Entomology and Agricultural Zoology, School of Agricultural Sciences, University of Thessaly, Thessaly 38446 Greece \\ ${ }^{7}$ School of Veterinary Medicine, University of California, Davis, California 95616 USA \\ ${ }^{8}$ Department of Entomology, University of California, Davis, California 95616 USA
}

Citation: Zhao, Z., C. Hui, R. E. Plant, M. Su, N. T. Papadopoulos, T. E. Carpenter, Z. Li, and J. R. Carey. 2019. The failure of success: cyclic recurrences of a globally invasive pest. Ecological Applications 00(00):e01991. 10.1002/eap.1991

\begin{abstract}
In the six decades since 1960, the oriental fruit fly, Bactrocera dorsalis (Hendel), has been announced successfully eradicated in California by the U.S. Department of Agriculture a total of 564 times. This includes eradication declarations in one city a total of 25 different years, in 12 cities 8-19 different years, and in 101 cities 2-7 different years. We here show that the false negatives in declaring elimination success hinge on the easily achieved regulatory criteria, which have virtually guaranteed the failure of complete extirpation of this pest. Analyses of the time series of fly detection over California placed on a grid of $100-\mathrm{km}^{2}$ cells revealed (1) partial success of the eradication program in controlling the invasion of the oriental fruit fly; (2) low prevalence of the initial detection in these cells is often followed by high prevalence of recurrences; (3) progressively shorter intervals between years of consecutive detections; and (4) high likelihood of early-infested cells also experiencing the most frequent outbreaks. Facing the risk of recurrent invasions, such short-term eradication programs have only succeeded annually according to the current regulatory criteria but have failed to achieve the larger goal of complete extirpation of the oriental fruit fly. Based on the components and running costs of the current programs, we further estimated the efficiency of eradication programs with different combinations of eradication radius, duration, and edge impermeability in reducing invasion recurrences and slowing the spread of the oriental fruit fly. We end with policy implications including the need for agricultural agencies worldwide to revisit eradication protocols in which monitoring and treatments are terminated when the regulatory criteria for declaring eradication are met. Our results also have direct implications to invasion biologists and agriculture policy makers regarding long-term risks of short-term expediency.
\end{abstract}

Key words: biological invasions; detection; eradication; invasion ecology; prevalence; risk; spatial process; surveillance; tephritids.

\section{INTRODUCTION}

Biological invasions by alien species are a growing threat to biodiversity conservation, regional economies, ecosystem functioning, and public health (Gurevitch and Padilla 2004, Ricciardi et al. 2017, Peng et al. 2019). Alien species in the United States have been estimated to cause major environmental damages and financial losses, adding up to nearly $\$ 120$ billion per year (Pimentel et al. 2005). When economically important invasive pests are detected, most agricultural agencies in threated regions immediately launch government-

Manuscript received 9 April 2019; revised 5 July 2019; accepted 19 July 2019. Corresponding Editor: Ahjond S. Garmestani.

${ }^{9}$ E-mail: zhzhao@cau.edu.cn mandated eradication programs. This is the case in the United States for Class A (high risk) insect pests including a dozen or more globally invasive species of tropical fruit flies (Carey 1991, USDA 2017). Declarations of eradication success have been issued by the California Department of Food and Agriculture (CDFA) for 100\% clearance of all detections of tropical fruit flies. However, such declarations have occurred intermittently in response to periodic recurrent outbreaks of these pests especially during the first decade after its initial discovery (Papadopoulos et al. 2013).

Eradication programs targeting alien invasive species are only feasible if the species has been detected early along its invasion continuum and management resources have been allocated rapidly. For example, the Asian citrus blackfly (Aleurocanthus woglumi) in the Florida 
Keys was successfully eradicated between 1934 and 1937 (Hoelmer and Grace 1989). If an eradication program can successfully control the further spread of alien invasive species and/or completely extirpate the problematic species from its invaded area, the program will be hailed for safeguarding the relevant international trade and agricultural industry (Lovett et al. 2016). However, failed eradication programs are also common, which often attract public skepticism and invasion denialism, affecting the whole cause of invasion management (Latombe et al. 2019). For instance, the campaign to eradicate the two imported fire ant species (Solenopsis invicta and $S$. richteri) from the southern United States has been dubbed "the Vietnam of Entomology" and a \$200-million disaster (Davidson and Stone 1989). It is, therefore, important to ensure the quality and efficiency of such eradication programs, with failed programs nonetheless providing lessons that often reveal the dynamics and mechanisms of invasion and its recurrences (Davis et al. 2016).

Eradication itself is a simple concept, i.e., the reduction of a target population to zero (Simberloff 2009). In principle the concept is precise, immutable and absolute. It is distinguished from pest management and control, which refers to the reduction of a population to acceptable levels, but not to ridding an area of a species (Liebhold and Tobin 2008). Although virtually all eradication programs cite zero population as the ultimate goal, there are vast differences between them with respect to thoroughness of planning, meticulousness of execution, length of program, and rigor of verification efforts (Stepan 2011).

Two different eradication paradigms can be applied in managing alien organisms. First, broadscale eradication programs (BEP) are long-term programs including major pre-eradication planning and multiple rigorous criteria met for declaring potential eradication success (Anderson et al. 2017). Such BEP are usually concerned with diseases (Stepan 2011, Anderson et al. 2017), wellestablished species of plants (Tasker and Westwood 2012, Dodd et al. 2017), mammals (Campbell and Donlan 2005, Jones et al. 2016), and insects (Myers et al. 2000 ), and often involve years of planning to ensure, that the preconditions are met for successful eradication and, that an evidence-based, meticulously vetted strategic framework is developed. Once launched these types of BEP require years if not decades to reduce the target population to the point where eradication success becomes a possibility (Papadopoulos et al. 2013).

The second paradigm is the emergency eradication program (EEP), which is typically short term in response to detection of a quarantine or health pest (Headrick and Goeden 1996). The EEP that is subject to such regulatory protocols are typically launched as emergency responses to newly detected invasive insects (USDA 2017). Eradication success is typically declared only using protocol-based policies rather than by hierarchies of criteria and the judgement of independent panels. That is, the same panels that have advised and shaped the EEP also declares eradication success of their programs (Carey et al. 2017a, $b$ ).

The oriental fruit fly (OFF, Bactrocera dorsalis (Hendel)), native to Southeast Asia, has invaded California since 1960 and has spread until 2017 across 75 counties (Manrakhan et al. 2015, Zeng et al. 2019). An EEP is triggered only by OFF detections, with no management prevention in place if there are no captures (Headrick and Goeden 1996). However, the recurrences of OFF after a successful EEP have been a common feature during the past 58-yr in California. Winning a battle, but losing the war; to date multiple invasive fruit flies have firmly established themselves in California (Zhao et al. 2019). To this end, we address the following questions: What are the invasion dynamics of OFF in California given the context of current EEPs? To address this question, we reconstructed the invasion of OFF based on records of detections from these EEPs. Why have the OFF not been eradicated with current EEPs? Where are the high-prevalence regions of OFF population for future recurrent outbreaks? To address these two questions, we mapped invasion prevalence and the risks of invasion and recurrences at the $10 \times 10 \mathrm{~km}$ grid cell level in California. To further discuss the policy implications, we further estimated the efficiency of simulated eradication programs, based on the current EEP and its running costs, with different combinations of eradication radius, duration, and edge impermeability, in reducing invasion recurrences and slowing invasion spread.

\section{Materials And Methods}

\section{Study region}

The study area encompassed the entire state of California. The climatic conditions of California vary widely, from hot desert to subarctic, depending on latitude, elevation, and proximity to the coast. There are wide distributions of fruit plants around the metropolitan area. We divided California into two groups: Northern California (NorCal) and Southern California (SoCal; Appendix S1: Fig. S1).

\section{Study species and data set}

The OFF is a notorious pest, which has spread to many countries and seriously threatens fruit and vegetable production (Manrakhan et al. 2015). Since 1950, the USDA and the CDFA have maintained a major project to monitor the distribution and prevent the invasion of OFF (Burnett et al. 2006). The USDA uses a trapping lure (Methyl eugenol) to detect OFF populations, capable of attracting them from a distance of up to $\sim 1 \mathrm{~km}$ (Steiner 1952). We collected all detection data from CDFA reports, as well as all historical captures in the California Plant Pest and Disease Reports available online. ${ }^{10}$ Each OFF detection was reported with

\footnotetext{
${ }^{10}$ https://www.cdfa.ca.gov
} 
information on detection time and the geographical location.

At the same time, a standard EEP has been implemented since 1960 to control OFF populations in California (Headrick and Goeden 1996). Once detected, an EEP is launched as the emergency response to local OFF invasions. This EEP typically only lasts for a short term (6 months) at a small spatial scale (USDA 2017), after which an eradication success can be declared if no new OFF individuals are captured during an interval of several months (approximately three life cycles). An EEP is the chain reaction of OFF population detection events, which forms the detection-eradication management cycle. Therefore most, if not all, OFF detections in California end up with a declaration of eradication success in the short term by USDA and CDFA. Additionally, eradication success has been declared hundreds of times with incessant recurrences of OFF population in the past 58 yr (Papadopoulos et al. 2013, Carey et al. 2017a).

\section{Data transformation}

To accurately capture invasion dynamics, we conducted detailed spatial analyses on the distributions of OFF detections using ArcGIS 10.0 (ESRI 2010). A base digital map (vectorized) of California was obtained from the U.S. Geological Survey (available online). ${ }^{11}$ We laid a lattice of $10 \times 10 \mathrm{~km}$ grid cells $\left(100 \mathrm{~km}^{2}\right)$ over the entire state and located each OFF detection within a particular cell for a particular year. We defined one detection in a cell to be the capture of $\geq 1$ OFF individuals in a given year. We used the variable $p_{i}(t)$ to indicate OFF detection $\left(p_{i}(t)=1\right)$ or non-detection $\left(p_{i}(t)=0\right)$ in cell $i$ in year $t$. No distinctions were made between a single and multiple detections in the same year within a cell.

We considered the status of a cell being infested if the OFF was detected in the cell during the year. Infested cells were divided into newly infested and recurrent ones. The number of detection years (DYs) was counted for each cell from 1960 through 2017. We marked the year of infestation as the calendar year of the first detection in a cell. For cell $i$, the number of detection years from year $t_{1}$ to $t_{2}$ is thus, $\mathrm{DY}_{i}\left(t_{1}, t_{2}\right)=\sum_{t=t_{1}}^{t_{2}} p_{i}(t)$. The year of infestation also marks the transition of invasion status for a cell from pre-infestation to post-infestation. The number of detection recurrences (DRs) was also counted for each cell: $\mathrm{DR}_{i}\left(t_{1}, t\right)=\mathrm{DY}_{i}\left(t_{1}, t\right)-1$. The recurrences can be either consecutive in the very next year of the first detection or after an interval of several years. See Appendix S1: Table S1 for heuristic descriptions of these variables.

\section{Invasion pattern and recurrence probability}

We calculated invasion prevalence (IP) to capture the invasion dynamics of OFF in California. IP indicates the

\footnotetext{
${ }^{11}$ https://www.usgs.gov/products/
}

frequency of OFF detections in an already infested cell. All cells were initially classified as pre-infestation. The IP for a cell is the fraction of DYs after the first year of detection. Specifically, for a particular cell $i$, its IP between year $t_{1}$ to $t_{2}$ can be defined as (Appendix S1: Fig. S2a, b): $\operatorname{IP}_{i}\left(t_{1}, t_{2}\right)=\mathrm{DY}_{i}\left(t_{1}, t_{2}\right) /\left(t_{2}-t_{1}+1\right)$.

We divided infested cells into two groups consisting of non-recurrent $(D Y=1)$ and recurrent cells $(D Y \geq 2)$. For recurrent cells, the intervals between two consecutive years of detections were computed to clarify recurrence patterns (note, the recurrent interval between year $t$ and $t+1$ is zero). For non-recurrent infested cells, the interval from infestation year to 2017 was used. Let $t_{1}$ represent the first year of detection in a cell; we estimated the recurrent probability (RP) after $x$ years from a reference year $t$ as the conditional probability RP $(x, t)=$ Prob (DY $\left.\left(t_{1}, t+x\right)=T+1 \mid \mathrm{DY}\left(t_{1}, t\right)=T\right)$, where RP $(1, t)$ represents the transmission rate for the recurrence immediately after year $t$ and $T$ represents the number of detection years (Clark et al. 2018). The RP was computed for 166 infested cells based on their time series (58-yr) from 1960 to 2017.

\section{Invasion risk and forecast}

Invasion risk (IR) measures the potential probability of OFF infestation for an empty cell with no previous OFF detections. To estimate the IR of an empty cell, we developed a spatial autoregressive (SAR) model of the temporal probability of OFF infestation (Hui and Richardson 2017, VerHoef et al. 2018), where an empty cell $j$ faces IR from adjacent invaded cells. The IR of an empty cell $j$ to become invaded in the next year is calculated as $\operatorname{IR}_{j}(t+1)=\beta_{j} \times \sum_{i=1}^{n} w_{i, j} p_{i}(t)+\varepsilon_{j}$, where the IR from the population in cell $i$ is weighted by the connectivity of an individual moving from cell $i$ to $j, w_{i}$, $j ; \beta_{j}$ and $\varepsilon_{j}$ are the regression coefficients and residues (Hui and Richardson 2017). In this SAR model, we considered the connectivity of 8 adjacent cells and also 16 cells neighboring these 8 adjacent cells to estimate IR by using the Spatial Analyst extension of ArcGIS (VerHoef et al. 2018). For a focal cell, we chose $w=2 / 3$ for the adjacent cells and $w=1 / 3$ for those neighboring these adjacent cells, to reflect that propagules released closer from the focal cell contribute more to its colonization (Horak et al. 2013). In order to obtain a reasonable long-term predication of OFF invasions, we ran the SAR model 10 time steps iteratively to estimate the patterns of invasion in the coming decade.

To estimate the eradication efficiency of the current EEPs, we conducted two simulations. First, we compared the invasion dynamics of the current practice (100\% EEPs following OFF detections) with the dynamics from two simulated scenarios $(50 \%$ and $0 \%$ EEPs after OFF detections). Second, for the current 100\% EEPs following OFF detections, we modified the three components of an EEP (eradication duration, 
eradication radius, and edge impermeability), each with 5 levels and a total of 125 combinations (Appendix S1), and compared the efficiency in terms of the recurrence rate, the spreading rate, the number of infested cells, and the number of recurrences from the simulations using a One-way ANOVA. Variance decomposition of these three components were conducted using the $\mathrm{R}$ package vegan (Dixon 2003) to assess each one's contribution to reducing invasion spread and recurrences.

\section{RESUlts}

\section{Invasion patterns}

The OFF was detected in California a total of 1,587 times in 166 out of 4,353 cells during the 58-yr period from 1960 through 2017 (Fig. 1a, b; Data S1). It was first detected in SoCal in 1960 at Los Angeles, followed by repeated captures nearby, with a continuous annual detection from 1969 through 2017 (Appendix S1: Fig. S3a). In NorCal, it was first detected in Santa Clara County, with two periods of continuous detections (1983-1998 and 2006-2013; Appendix S1: Table S2, Fig. S3b). Contrasting to only three cells in NorCal with IP $>10 \%, 50$ cells in SoCal had IP $>10 \%$, with two cells having IP $>30 \%$. The DYs of infested cells varied greatly and had different recurrence patterns (Appendix S1: Fig. S4). EEP has been conducted in all infested cells, with the cost of each EEP increasing with the number of detections in a cell. During OFF invasion processes, the cost of these eradication programs has mounted to $\$ 610$ million per infested cell on average (Appendix S1: Fig. S5). Accompanied with eradication declaration after each OFF detection, these collective trends revealed six decades of OFF invasion throughout much of California.

\section{Invasion prevalence and recurrences}

Of the 166 infested cells there were $46.4 \%$ (77) that have only been detected once, representing the success of EEPs, while the other 53.6\% (89) cells reported 487 recurrences, representing the failures of EEPs, with two cells in Los Angeles experienced more than $20 \mathrm{yr}$ of detections (Fig. 2a; Appendix S1: Fig. S6). The number of newly infested cells in each year peaked between 1980 and 2000, while the number of cells experiencing recurrent infestations has been continuously rising, overshooting the accumulated number of newly infested cells after 1985 (Fig. 2b). The within-cell recurrence intervals ranged between 0 and $26 \mathrm{yr}$ including 162 recurrences without intervals, 192 with 1 to 4 yr interval, 94 with 5-10 yr interval, 36 with 11-20 yr interval, and three with more than $21 \mathrm{yr}$ of recurrence interval (Fig. 2c). The no-detection intervals from infestation of nonrecurred cells were varied from 1 to $20 \mathrm{yr}$ (Fig. 2d).

Among cells with 2-12 yr of detections at a reference time $t$ (Fig. 3a), approximately $80 \%$ experienced recurrences in the next year $(\operatorname{RP}(1, t) \approx 0.8)$. The recurrent probability of an infested cell increased year on year, reaching a saturation $27 \mathrm{yr}$ after the first detection in California (Fig. 3b).

\section{Invasion risk and forecast}

Of the total 1,669 currently empty cells in SoCal, $23.6 \%$ cells face a low invasion risk in the following year $(\operatorname{IR}[2018]<0.05)$, while $7.7 \%$ face a high invasion risk $($ IR[2018] $>0.5)$. When projected over the next $10 \mathrm{yr}$, $34.6 \%$ cells still face a low invasion risk (IR [2028] $<0.05$ ), while $12.4 \%$ face a high invasion risk (IR [2028] > 0.5; Fig. 4). Of the 2,518 currently empty cells in NorCal, $12.9 \%$ cells face a low invasion risk in the following year $(\operatorname{IR}[2018]<0.05)$, while $5.2 \%$ face a high invasion risk $($ IR[2018] $>0.5)$. When projected over the next $10 \mathrm{yr}, 21.1 \%$ cells still face a low invasion risk (IR [2028] $<0.05$ ), while $8.5 \%$ face a high invasion risk (IR [2028] >0.5; Fig. 4). Taken together, the recurrences suggest that the invasion is continuingly expanding in California (Appendix S1: Fig. S7). Although most local EEPs declared eradication success after achieving their own regulatory criteria, only $46.4 \%$ have succeeded in preventing invasion recurrences, and collectively they have failed to achieve the larger goal of regional OFF extirpation.

Under the current practice of 100\% EEPs following an OFF detection, the number of yearly infested cells has exhibited great fluctuations in the past six decades, reaching around 20 infested cells per year in the recent decade. Under $50 \%$ or $0 \%$ EEPs following an OFF detection, the number of yearly infested cells would soar to 89 (4.5 times) and 166 (8.3 times) in the recent decade, respectively (Appendix S1: Fig. S8). Evidently, the current practice of $100 \%$ EEPs have significantly slowed the invasion of OFF, albeit still unable to reverse the tide (Appendix S1: Fig. S8).

Increasing eradication duration can significantly reduce the recurrence rate and the spreading rate, as well as the numbers of infested cells and recurrences, suggesting a duration of 12 months, instead of the 6month duration of the current practice, as an optimal option (Fig. 5a-d). Changing eradication radius had a significant effect on the spreading rate but showed little effect on other metrics of efficiency (Fig. 5e-h). Increasing the edge impermeability can also drastically reduce the rates of recurrence and spreading, as well as the number of infested cells (Fig. 5i-1), highlighting the importance of preventing spillovers for efficient OFF control. Overall, increasing eradication duration showed a larger effect to reduce invasion spread and recurrence than increasing eradication radius and edge impermeability (Appendix S1: Fig. S9a-d), with the increase of edge impermeability still better than the increase of eradication radius (Appendix S1: Fig. S9e, f). Moreover, compared with eradication radius and edge 
a
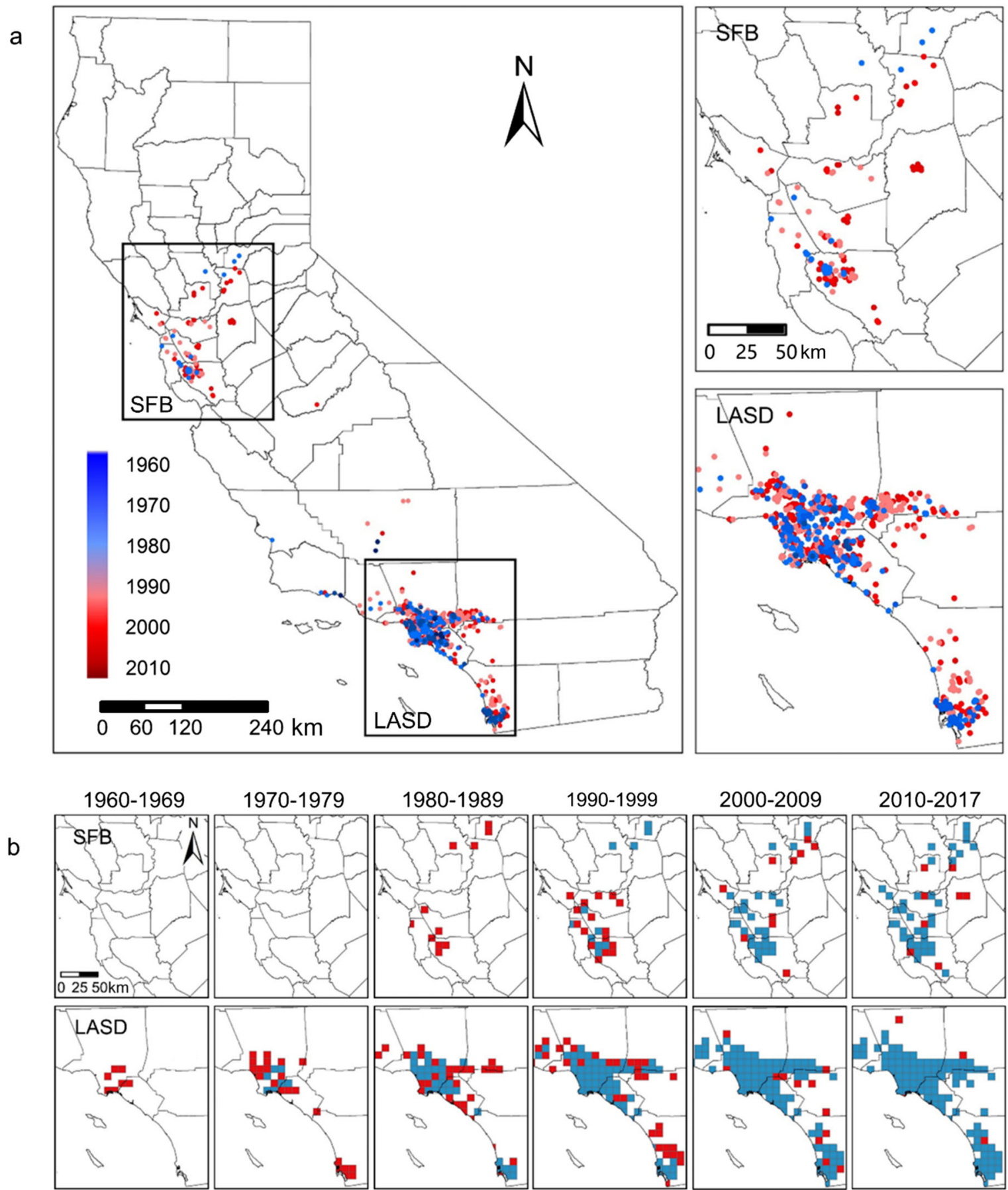

FIG. 1. Distribution of the detection of the oriental fruit flies (Bactrocera dorsalis; OFF) in California during 1960-2017. (a) The distribution was concentrated in two areas: San Francisco Bay (SFB) and Los Angeles Basin and San Diego metropolitan (LASD). (b) The invasion progression was shown at a decadal interval in SFB and LASD. Red cells indicate newly infested cells in the decade, and blue cells indicate recurrent cells that have already been infested in the previous decade.

impermeability, eradication duration also contributed the most in explaining the number of recurrences and infested cells (Appendix S1: Fig. S10a, b). However, when considering the implication of these alternative components of an EEP, we have to face a conundrum emerging from these simulations: to halve the invasion (and presumably its negative impact) requires double the management cost. 

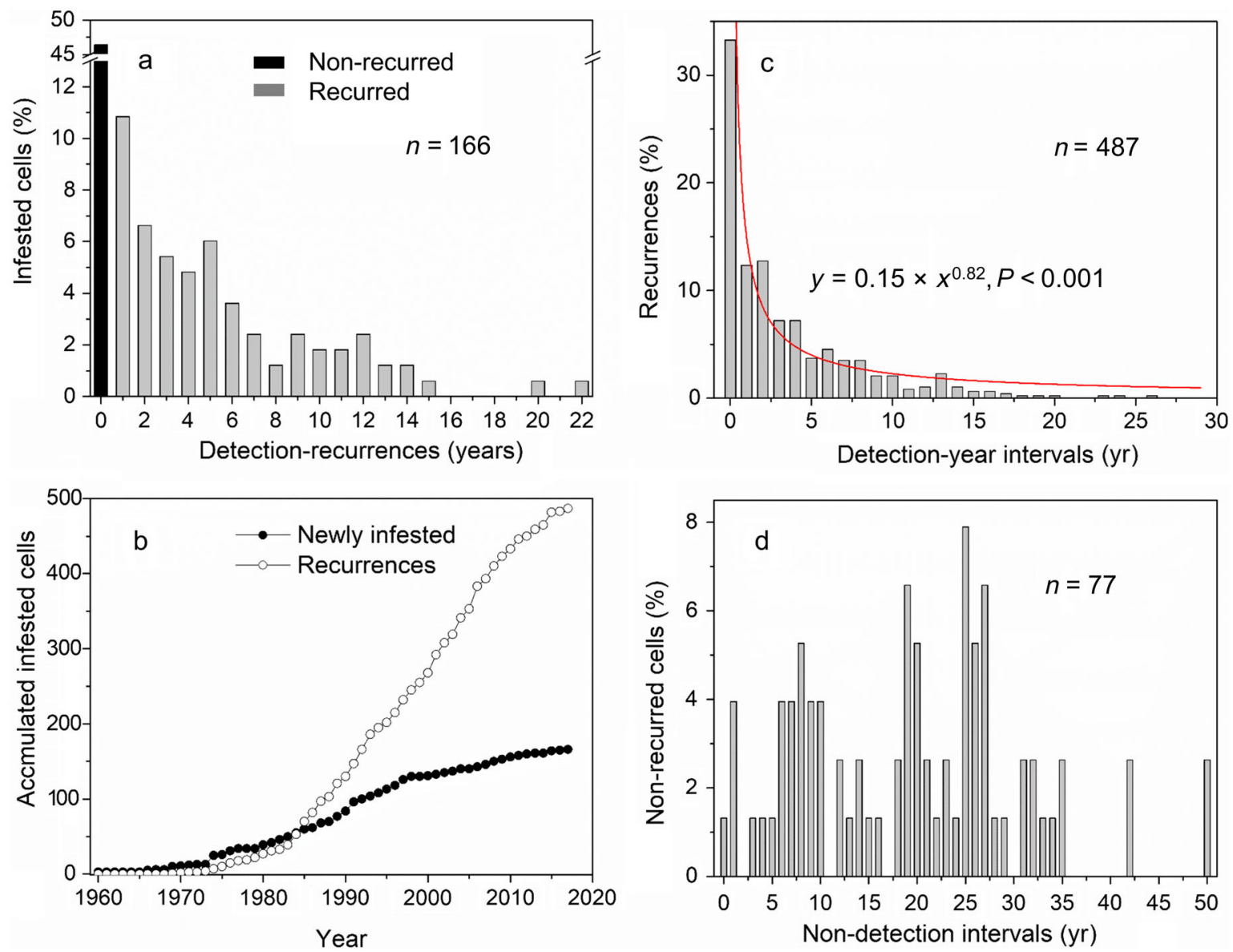

FIG. 2. The infestation patterns of infested cells in California. (a) The frequency distribution of recurrent detections for infested cells, with the black column indicating infested cells but without recurrences. (b) Accumulated numbers of newly infested cells and recurrences. (c) Pattern of infested cells between two continuous detection years (DYs) of recurred cells. (d) Patterns of non-recurred cells from infestation year to 2017.

\section{DisCUSSION}

\section{Invasion patterns}

Despite the due diligence, quick responses and massive expenditures of government agencies to prevent the entry and establishment of OFFs, the fly has aperiodically recurred in California, with the invasion reappearing in many cells every $1-5 \mathrm{yr}$ (Papadopoulos et al. 2013). Almost one-half of the infested cells $(46.4 \%)$ had no recurrences, indicating a partial success of the current EEPs that have reduced invasion and recurrences when compared to $50 \%$ and $0 \%$ EEPs following an OFF detection (Appendix S1: Fig. S7). However, the OFF has been expanding its range from scores of locations to many hundreds of inhabitable cells throughout the region (Bennett et al. 2013). As the population increases in both density and occupancy within infested cells, it becomes increasingly difficult to eradicate and control (Myers et al. 2000, Muzika 2017). Consequently, we observed an ever-shortening recurrent interval and more severe outbreaks in infested cells after each EEP (Appendix S1: Fig. S4). Moreover, infested cells that have not experienced any recurrences could indicate either a successful EEP or that they are in a waiting phase for next recurrences (Tobin et al. 2014, Wilson et al. 2018). To this end, although the contextual complexity will inevitably lead to different eradication outcomes (Hoffmann and Courchamp 2016), a long-term surveillance system for sustainable monitoring of posteradication areas is clearly needed, to both certify the efficiency of EEP and monitor possible OFF resurgence from sub-detectable populations (Anderson et al. 2017, Zhao et al. 2019).

\section{Invasion prevalence and risk}

Invasion risk of an empty cell, in general, is much less probable than recurrence in an adjacent infested cell (Fig. 3a). This is largely due to the fact that alien species must negotiate a number of barriers to become established and invasive in new habitats (Hui and Richardson 

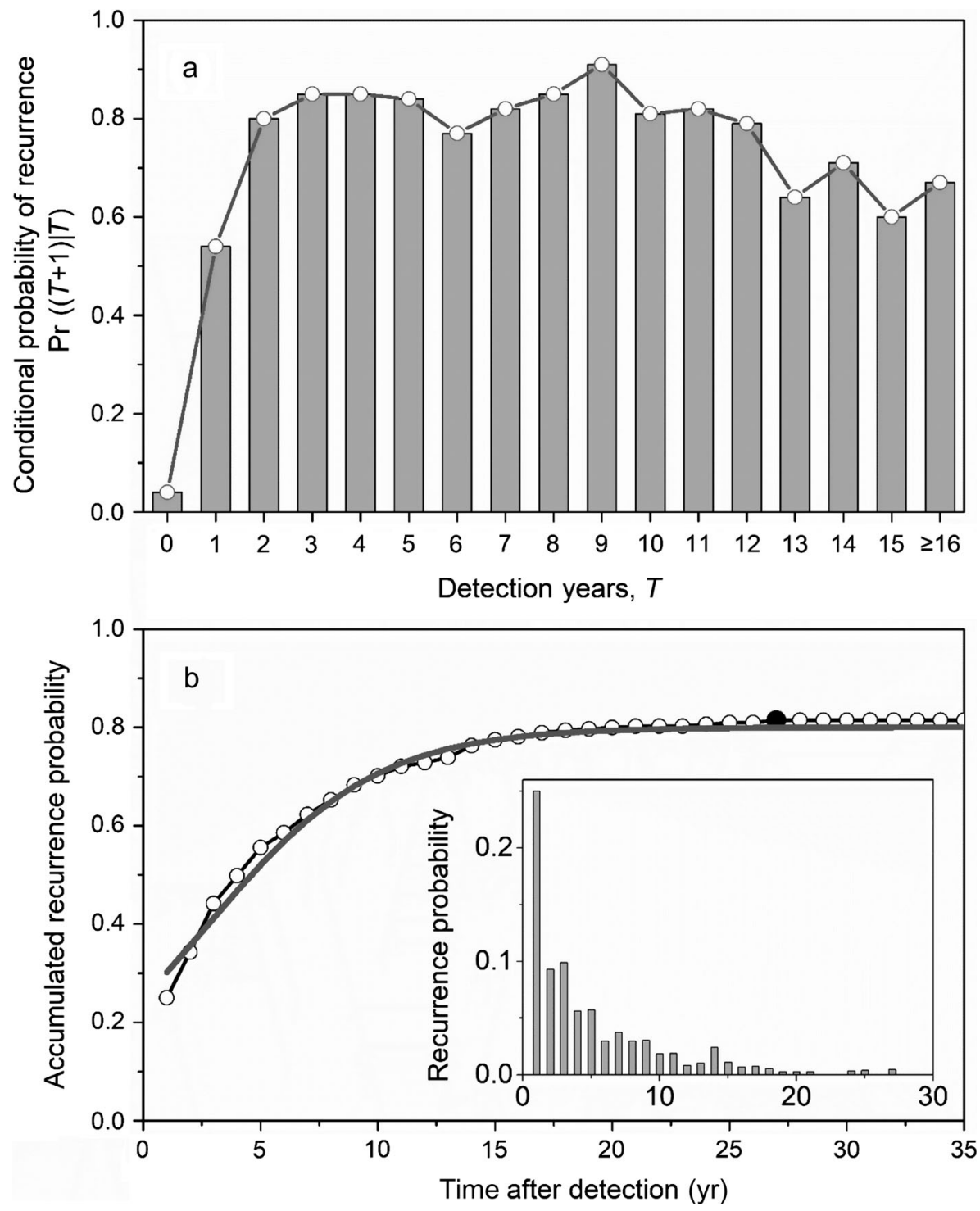

FIG. 3. Instantaneous and accumulative probability of invasion recurrence. (a) The transmission rate as a function of the number of detection years. (b) The accumulative probability of recurrence, fitted to a sigmoid function (gray curve; $y=0.80$ / $\left.\left(1+e^{-(0.28 x-0.78)}\right), P<0.001\right)$.

2017), while recurrence only reflects population compensation after experiencing low population levels from environmental fluctuations and/or eradication (Manrakhan et al. 2015, Lutscher and Musgrave 2017, Hausch et al. 2018). Nonetheless, infested populations can serve as the propagule source to the invasion of other empty cells, while the sub-detectable population after successful eradication programs can also serve as propagule reservoirs for recurrent invasions (Bennett et al. 2013, Baker et al. 2017); both make EEP challenging and arbitrary (Liebhold and Tobin 2008, Ekesi et al. 2016).

We only considered invasion risks from contacting adjacent infested cells (using the SAR model), while jumping transmission caused by human-mediated translocation made invasion predication more complex and uncertain (Menke et al. 2018). Nonetheless, the assessment of invasion prevalence and risk provides us a reliable picture on the patterns and underlying mechanisms of alien organisms (Lantschner et al. 2017). The reasonable performance of the SAR model when predicting invasion prevalence and risk suggests it a robust management tool when little is known about auxiliary data collected opportunistically or through citizen scientists (Bauman et al. 2018). Future development on the SAR model could consider more realistic connectivity weights to reflect, for instance, local transportation and trading networks that translocate invasive propagules (Pacifici et al. 2017). 


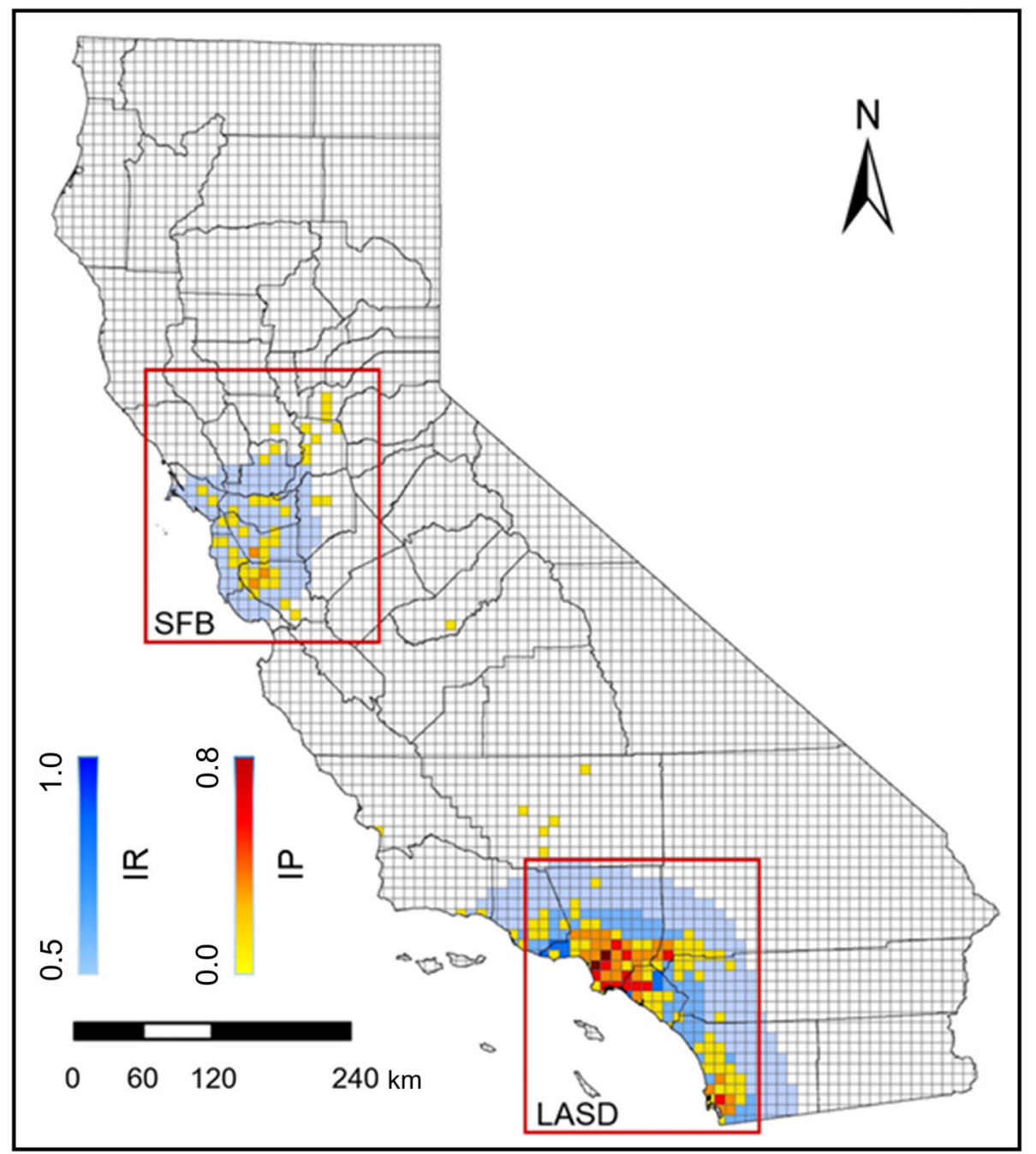

FIG. 4. The invasion patterns and risk of OFF infestation. (a) Invasion prevalence (IP; yellow-red) and invasion risk (IR; blue shade) of OFF invasion. IR is estimated from the SAR model of non-infested empty cells; the Standardized residuals (0.5) is the threshold to indicate potential IR based on binary presence/absence data of the oriental fruit fly invasions of non-infested cell (empty cells) in California.

\section{Invasion management and efficiency}

The cost of running an average eradication program targeting an established OFF population was on average $\$ 12$ million after each detection in 2012, which has rapidly ballooned into \$200 million per year in recent decades (Suckling et al. 2016) This has hampered many eradication programs in developing countries. For instance, due to lack of funding for EEPs, the OFF first invaded Kenya in 2003 and has spread across 42 African countries up to 2018 (Zeng et al. 2019). In California, the OFF has only established in a relatively limited area, suggesting that EEPs have played an important role in controlling and containing this invasive fruit fly. However, complete eradication would incur a much higher cost and require a wider collaboration of policy makers, farmers, technicians, and scientists in a long-term eradication program. A precise map of invaded and risky areas could certainly help reduce the cost of eradication programs and increase management efficiency (Spring et al. 2017, Williams et al. 2018), while efficiently preventing the spread of OFF and eliminating recurrences are particularly important to ensure the efficacy of eradication programs. As eradication duration, radius, and edge impermeability are important components of an EEP, designing a cost-efficient combination of these components for different control targets (e.g., reducing invasion spread vs. recurrences) becomes crucial for sustainable and efficient invasion management (Mcclelland et al. 2018, Zhao et al. 2019). The rule of thumb emerged from our simulations can be of help for optimizing EEP components: to halve the invasion requires double the cost. Moreover, in infested areas the prevention of spillover to adjacent empty cells should be 
(a)

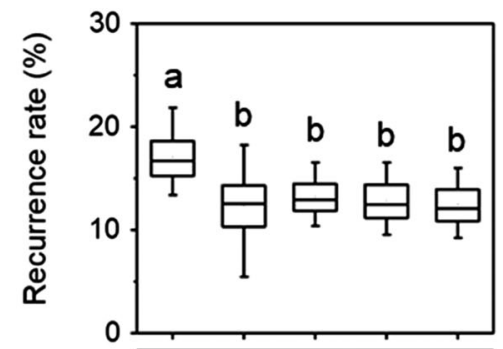

(b)

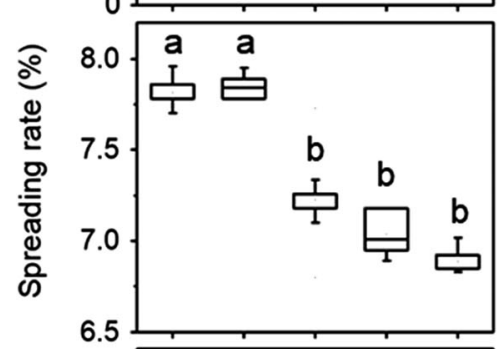

(c)

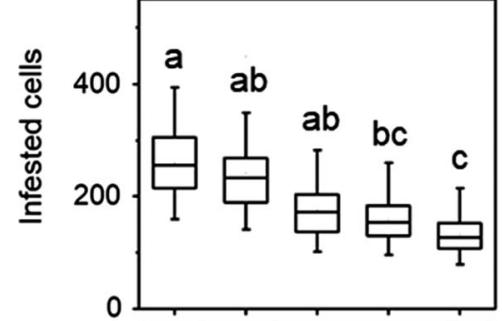

(d)

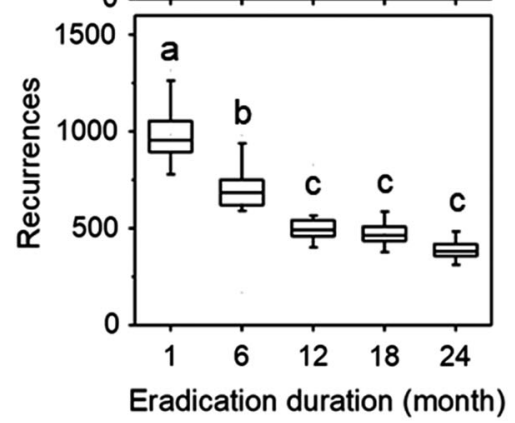

(e)

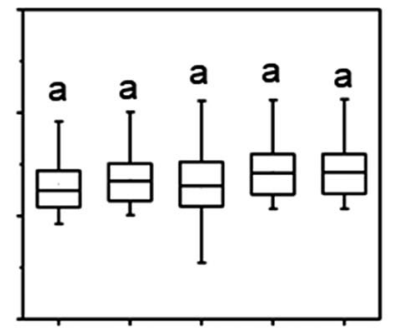

(f)

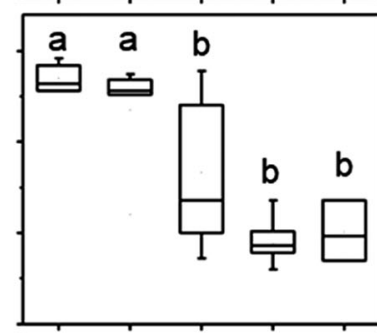

(g)

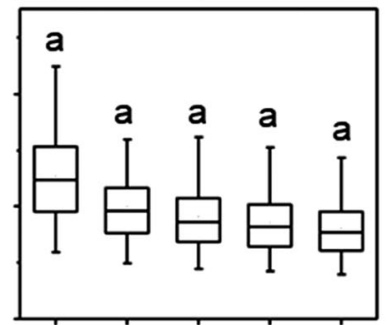

(h)

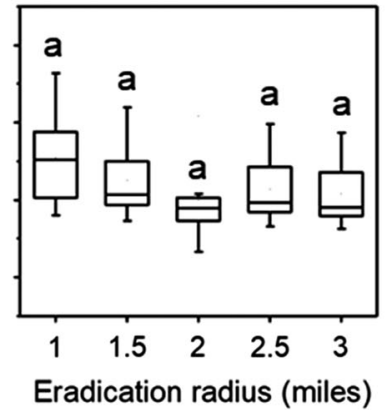

(i)

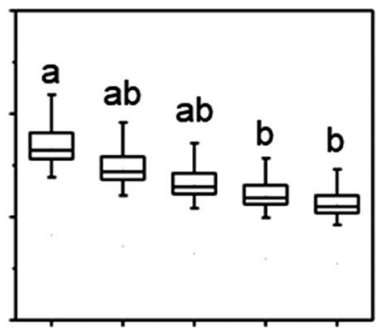

(j)

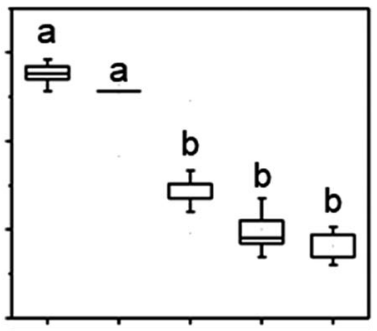

(k)

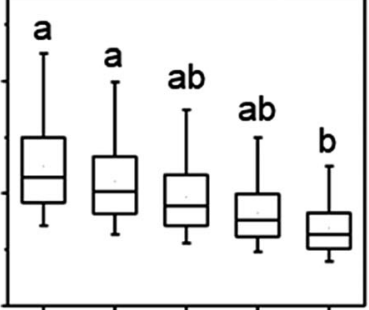

(I)

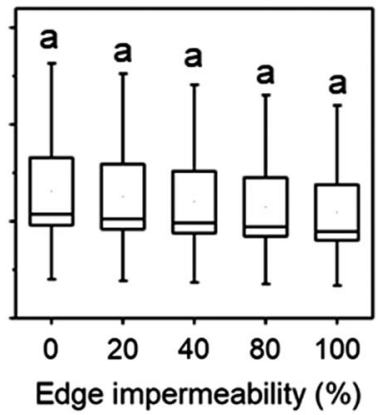

FIG. 5. Effects of three emergency eradication program (EEP) components (eradication duration, radius, and edge impermeability) on the eradication efficiency. In particular, the effects of eradication duration (month) on (a) recurrence rate, (b) spreading rate, (c) number of infested cells, and (d) number of recurrences; the effects of eradication radius (miles) on (e) recurrence rate, (f) spreading rate, $(\mathrm{g})$ number of infested cells, and $(\mathrm{h})$ number of recurrences; the effects of edge impermeability (\%) on (i) recurrence rate, (j) spreading rate, $(\mathrm{k})$ number of infested cells, and (l) number of recurrences. Different letters represent significant differences (see Appendix S1: Figs. S9, S10 for details).

prioritized, while in high-risk areas, more powerful surveillance systems are needed to push down the threshold of detection (Headrick and Goeden 1996, Simberloff 2009, Suckling et al. 2016). In principle, a wellcoordinated broadscale eradication program should be developed based on accurate distribution and surveillance, which then have the potential to completely extirpate this pest in high prevalence regions (Carey et al. 2017a, b, Muller et al. 2019, Schwab et al. 2019).

\section{Invasion mechanism}

The invasion dynamics of invasive alien OFF populations with highly spatial heterogeneity suggests three nonexclusive trajectories (Appendix S1: Fig. S11a, b). Trajectory I depicts the invasion pathway of incessant reintroductions of OFF populations to the epidemic area from outside California (Hulme et al. 2008, Fera et al. 2017). This is supported by the interception data at ports of entry worldwide with annual OFF interceptions in at least tens of thousands. Small numbers of OFF can be transported as stowaway in commodities and (re)introduced as escapees (Work et al. 2005, McCullough et al. 2006, Hulme et al. 2008). Stowaways are directly associated with transportation but arrive independently from specific commodity/contaminant. The air corridor pathway highlights the role that transport infrastructures play in the re-introduction of alien 
species (Lutscher and Musgrave 2017). Trajectory II depicts partial success in infested cells but without recurrences, which could indicate the effectiveness of the EEP in these cells. Trajectory III depicts the resurgence of an undetectable population following an EEP (or due to inefficient surveillance) and often after a latent period. This is potentially the case in Los Angeles, where the grid cell has experienced more than 20 recurrences. As the OFF population continued to recur in the same locations, it is highly likely that a small population has permanently established in these areas (Appendix S1: Fig. S4). Regions with high prevalence or high risk of invasion recurrences should, thus, receive more intensive surveillance to avoid the invasion dynamics of Trajectory I and III, with better coordination among exit/entry inspection, USDA, scientists, and citizens (Gurevitch et al. 2011). In particular, the invasion trajectory III, that sub-detectable populations of potentially established flies can grow and reach the detectable level, could have profound policy implications, including that (1) the eradication cannot be achieved solely by reducing introductions through controlling invasion pathways; (2) growers should be given information to make informed decisions regarding uncertainties and risks involving spillover and resurgence of sub-detectable populations; (3) costly surveillance programs can be focused more on areas with high recurrent risks. Also, costly surveillance programs can be more strategically focused based on data analysis of invasion ecology and on the historical knowledge of regional outbreak risks rather than on post-eradication "resets" where trapping programs in all regions are identical regardless of their outbreak history (Hoffmann et al. 2019). Finally, understanding the nature of the invasion ecology of OFF will enable invasion biologists to identify and derive basic principles of spatial invasions that are general. These can include questions ranging from the speed and nature of OFF spread to the importance of preadaptation in establishment and naturalization phases of the invasion (Karban and Orrock 2018, Zhao et al. 2019).

Local eradication success, even with high confidence (e.g., 0.95 probability of invasion free in each of 10 local areas), often faces a certain regional failure for eradication (e.g., 0.4 probability of alien establishment in the 10 local areas; Anderson et al. 2017), due to inflated persistence at the regional scale for the ensemble of local populations (Hui et al. 2017). In addition, high-risk areas with sub-detectable populations can often serve as the source for ongoing OFF invasion and resurgence, making local-scale EEPs often futile and arbitrary. Early established OFF populations could drive secondary invasions and boost recurrences of OFFs in surrounding areas (Bertelsmeier and Keller 2018). It is therefore important to establish long-term eradication programs and the surveillance of post-eradication areas to avoid the resurgence of OFF populations and ensure the efficiency of EEPs.

\section{CONCLUSION}

The OFF detection fluctuated widely during the past $58 \mathrm{yr}$, with ongoing invasions despite intensive eradication effort. Our analysis revealed inconsistent declarations of eradication success and pinpointed a few areas with high prevalence and high risks for ongoing OFF invasion and recurrence. The case of OFF invasion and management in California highlights the enormous challenges associated with detecting small populations even with dedicated detection technologies (Trajectory III). The invasion dynamics followed the three trajectories in different areas, suggesting the necessity for optimizing eradication effort (eradication duration, radius, and edge impermeability) based on different levels of invasion prevalence and risks to achieve the sustainable management goal (Myers et al. 2000, Ricciardi et al. 2017). To this end, we call for a global team from across the board to coordinate and share data to better monitor the ongoing biological invasions (Tobin et al. 2014, Liebhold et al. 2016, Zhao et al. 2019).

ACKNOWLedgments

We thank the California Department of Food and Agriculture for providing us with tephritid capture data. We thank Prof. Tim Coulson at the Department of Zoology, Oxford University and Christian Nansen and Sarah Silverman at the Department of Entomology, UC Davis for providing comments to our initial draft. We thank to Xiangfeng Shi, Hao Li, and Jing Wei for assistance of data arrangements. We also thank to Ahjond Garmestani and two anonymous reviewers for their constructive comments and advice on our manuscript. Z. Zhao, N. T. Papadopoulos, and J. R. Carey collected the data set of invasive alien flies. Z. Zhao conducted the statistical analysis and wrote the first draft. Z. Zhao, C. Hui, R. E. Plant, M. Su, and J. R. Carey discussed the analysis and revised the first draft. All authors approved the final version. We declare no competing interests. This work is supported by the National Key R\&D Program of China (No. 2017YFD0200400), the National Science Foundation (Nos. 31770453; 31770470), and the National Key R\&D Program of Ningxia (2017BY080).

\section{Literature Cited}

Anderson, D. P., A. M. Gormley, D. S. L. Ramsey, G. Nugent, P. A. J. Martin, M. Bosson, P. Livingstone, and A. E. Byrom. 2017. Bio-economic optimization of surveillance to confirm broadscale eradications of invasive pests and diseases. Biological Invasions 19:2869-2884.

Baker, C. M., J. C. Hodgson, E. Tartaglia, and R. H. Clarke. 2017. Modelling tropical fire ant (Solenopsis geminata) dynamics and detection to inform an eradication project. Biological Invasions 19:2959-2970.

Bauman, D., T. Drouet, M. J. Fortin, and S. Dray. 2018. Optimizing the choice of a spatial weighting matrix in eigenvector-based methods. Ecology 99:2159-2166.

Bennett, J. R., M. Vellend, P. L. Lilley, W. K. Cornwell, and P. Arcese. 2013. Abundance, rarity and invasion debt among exotic species in a patchy ecosystem. Biological Invasions 15:707-716.

Bertelsmeier, C., and L. Keller. 2018. Bridgehead effects and role of adaptive evolution in invasive populations. Trends in Ecology \& Evolution 33:527-534. 
Burnett, W., W. Enkerlin, J. F. Gilmore, P. A. Rendon, C. Smith, and J. L. Zavala. 2006. International panel for review of the fruit fly surveillance programs in the United States. United States Department of Agriculture/APHIS /PPQ/Fruit Fly Program, Riverdale, Maryland, USA.

Campbell, K., and C. J. Donlan. 2005. Feral goat eradications on islands. Conservation Biology 19:1362-1374.

Carey, J. R. 1991. Establishment of the Mediterranean fruit-fly in California. Science 253:1369-1373.

Carey, J. R., N. Papadopoulos, and R. Plant. 2017a. The 30year debate on a multi-billion-dollar threat: tephritid fruit fly establishment in California. American Entomologist 63:100113.

Carey, J. R., N. Papadopoulos, and R. Plant. 2017b. Tephritid pest populations oriental fruit fly outbreaks in California: 48 consecutive years, 235 cities, 1,500 detections-and counting. American Entomologist 63:232-236.

Clark, N. J., K. Wells, and O. Lindberg. 2018. Unravelling changing interspecific interactions across environmental gradients using Markov random fields. Ecology 99:12771283.

Davidson, N. A., and N. D. Stone. 1989. Imported fire ants. Pages 196-217 in D. A. Dahlsten and R. Garcia, editors. Eradication of exotic pests. Yale University Press, New Haven, Connecticut, USA.

Davis, A. J., M. B. Hooten, R. S. Miller, M. L. Farnsworth, J. Lewis, M. Moxcey, and K. M. Pepin. 2016. Inferring invasive species abundance using removal data from management actions. Ecological Applications 26:2339-2346.

Dixon, P. 2003. VEGAN, a package of R functions for community ecology. Journal of Vegetation Science 14:927-930.

Dodd, A. J., N. Ainsworth, C. E. Hauser, M. A. Burgman, and M. A. McCarthy. 2017. Prioritizing plant eradication targets by reframing the project prioritization protocol (PPP) for use in biosecurity applications. Biological Invasions 19:859-873.

Ekesi, S., M. De Meyer, S. A. Mohamed, M. Virgilio, and C. Borgemeister. 2016. Taxonomy, ecology, and management of native and exotic fruit fly species in Africa. Annual Review of Entomology 61:219-238.

ESRI. 2010. ArcGIS desktop: release 10.0. Environmental Systems, Redlands, California, USA.

Fera, S. A., M. D. Rennie, and E. S. Dunlop. 2017. Broad shifts in the resource use of a commercially harvested fish following the invasion of dreissenid mussels. Ecology 98:1681-1692.

Gurevitch, J., G. A. Fox, G. M. Wardle, and D. Taub. 2011. Emergent insights from the synthesis of conceptual frameworks for biological invasions. Ecology Letters 14:407-418.

Gurevitch, J., and D. K. Padilla. 2004. Are invasive species a major cause of extinctions? Trends in Ecology \& Evolution 19:470-474.

Hausch, S., S. M. Vamosi, and J. W. Fox. 2018. Effects of intraspecific phenotypic variation on species coexistence. Ecology 99:1453-1462.

Headrick, D. H., and R. D. Goeden. 1996. Issues concerning the eradication or establishment and biological control of the Mediterranean fruit fly, Ceratitis capitata (Wiedemann) (Diptera: Tephritidae), in California. Biological Control 6:412421.

Hoelmer, K. A., and J. K. Grace. 1989. Citrus blackfly. Pages 147-165 in D. A. Dahlsten and R. Garcia, editors. Eradication of exotic pests. Yale University Press, New Haven, Connecticut, USA.

Hoffmann, B. D., and F. Courchamp. 2016. Biological invasions and natural colonisations: Are they that different? Neobiota 29:1-14

Hoffmann, J. H., V. C. Moran, and M. P. Hill. 2019. Conceptualizing, categorizing and recording the outcomes of biological control of invasive plant species, at a population level. Biological Control 133:134-137.

Horak, J., C. Hui, N. Roura-Pascual, and D. Romportl. 2013. Changing roles of propagule, climate, and land use during extralimital colonization of a rose chafer beetle. Naturwissenschaften 100:327-336.

Hui, C., G. A. Fox, and J. Gurevitch. 2017. Scale-dependent portfolio effects explain growth inflation and volatility reduction in landscape demography. Proceedings of the National Academy of Sciences USA 114:12507-12511.

Hui, C., and D. M. Richardson. 2017. Invasion dynamics. Oxford University Press, Oxford, UK.

Hulme, P. E., et al. 2008. Grasping at the routes of biological invasions: a framework for integrating pathways into policy. Journal of Applied Ecology 45:403-414.

Jones, H. P., et al. 2016. Invasive mammal eradication on islands results in substantial conservation gains. Proceedings of the National Academy of Sciences USA 113:40334038.

Karban, R., and J. L. Orrock. 2018. A judgment and decisionmaking model for plant behavior. Ecology 99:1909-1919.

Lantschner, M. V., T. H. Atkinson, J. C. Corley, and A. M. Liebhold. 2017. Predicting North American Scolytinae invasions in the Southern Hemisphere. Ecological Applications $27: 66-77$

Latombe, G., et al. 2019. A four-component classification of uncertainties in biological invasions: implications for management. Ecosphere 10:e02669.

Liebhold, A. M., and P. C. Tobin. 2008. Population ecology of insect invasions and their management. Annual Review of Entomology 53:387-408.

Liebhold, A. M., et al. 2016. Eradication of invading insect populations: from concepts to applications. Annual Review of Entomology 61:335-352.

Lovett, G. M., et al. 2016. Nonnative forest insects and pathogens in the United States: impacts and policy options. Ecological Applications 26:1437-1455.

Lutscher, F., and J. A. Musgrave. 2017. Behavioral responses to resource heterogeneity can accelerate biological invasions. Ecology 98:1229-1238.

Manrakhan, A., J. H. Venter, and V. Hattingh. 2015. The progressive invasion of Bactrocera dorsalis (Diptera: Tephritidae) in South Africa. Biological Invasions 17:2803-2809.

Mcclelland, G. T. W., R. Altwegg, R. J. van Aarde, S. Ferreira, A. E. Burger, and S. L. Chown. 2018. Climate change leads to increasing population density and impacts of a key island invader. Ecological Applications 28:212-224.

McCullough, D. G., T. T. Work, J. F. Cavey, A. M. Liebhold, and D. Marshall. 2006. Interceptions of nonindigenous plant pests at US ports of entry and border crossings over a 17-year period. Biological Invasions 8:611-630.

Menke, S. B., P. S. Ward, and D. A. Holway. 2018. Long-term record of Argentine ant invasions reveals enduring ecological impacts. Ecology 99:1194-1202.

Muller, F. A., N. P. Dias, M. S. Gottschalk, F. R. M. Garcia, and D. E. Nava. 2019. Potential distribution of Bactrocera oleae and the parasitoids Fopius arisanus and Psyttalia concolor, aiming at classical biological control. Biological Control 132:144-151.

Muzika, R. M. 2017. Opportunities for silviculture in management and restoration of forests affected by invasive species. Biological Invasions 19:3419-3435.

Myers, J. H., D. Simberloff, A. M. Kuris, and J. R. Carey. 2000. Eradication revisited: dealing with exotic species. Trends in Ecology \& Evolution 15:316-320.

Pacifici, K., B. J. Reich, D. A. W. Miller, B. Gardner, G. Stauffer, S. Singh, A. McKerrow, and J. A. Collazo. 2017. 
Integrating multiple data sources in species distribution modeling: a framework for data fusion. Ecology 98:840-850.

Papadopoulos, N. T., R. E. Plant, and J. R. Carey. 2013. From trickle to flood: the large-scale, cryptic invasion of California by tropical fruit flies. Proceedings of the Royal Society B 280:20131466

Peng, S., N. L. Kinlock, J. Gurevitch, and S. L. Peng. 2019. Correlation of native and exotic species richness: a global metaanalysis finds no invasion paradox across scales. Ecology 100: e02552.

Pimentel, D., R. Zuniga, and D. Morrison. 2005. Update on the environmental and economic costs associated with alien-invasive species in the United States. Ecological Economics 52:273-288

Ricciardi, A., et al. 2017. Invasion science: a Horizon Scan of emerging challenges and opportunities. Trends in Ecology \& Evolution 32:464-474.

Schwab, S. R., C. M. Stone, D. M. Fonseca, and N. H. Fefferman. 2019. (Meta) population dynamics determine effective spatial distributions of mosquito-borne disease control. Ecological Applications 29:e01856.

Simberloff, D. 2009. We can eliminate invasions or live with them. Successful management projects. Biological Invasions 11:149-157.

Spring, D., L. Croft, and T. Kompas. 2017. Look before you treat: increasing the cost effectiveness of eradication programs with aerial surveillance. Biological Invasions 19:521-535.

Steiner, L. F. 1952. Methyl eugenol as an attractant for oriental fruit fly. Journal of Economic Entomology 45:241-248.

Stepan, N. L. 2011. Eradication: Ridding the world of disease forever? American Journal of Epidemiology 175:1088-1089.

Suckling, D. M., J. M. Kean, L. D. Stringer, C. Caceres-Barrios, J. Hendrichs, J. Reyes-Flores, and B. C. Dominiak. 2016. Eradication of tephritid fruit fly pest populations: outcomes and prospects. Pest Management Science 72:456-465.
Tasker, A. V., and J. H. Westwood. 2012. The U.S. witchweed eradication effort turns 50: a retrospective and look-ahead on parasitic weed management. Weed Science 60:267-268.

Tobin, P. C., J. M. Kean, D. M. Suckling, D. G. McCullough, D. A. Herms, and L. D. Stringer. 2014. Determinants of successful arthropod eradication programs. Biological Invasions $16: 401-414$

USDA. 2017. National plant health emergency management framework. Government Printing Office, Washington, D.C., USA.

VerHoef, J. M., E. E. Peterson, M. B. Hooten, E. M. Hanks, and M. J. Fortin. 2018. Spatial autoregressive models for statistical inference from ecological data. Ecological Monographs 88:36-59.

Williams, P. J., M. B. Hooten, J. N. Womble, G. G. Esslinger, and M. R. Bower. 2018. Monitoring dynamic spatio-temporal ecological processes optimally. Ecology 99:524-535.

Wilson, C. M., R. N. Schaeffer, M. L. Hickin, C. M. Rigsby, A. F. Sommi, C. S. Thornber, C. M. Orians, and E. L. Preisser. 2018. Chronic impacts of invasive herbivores on a foundational forest species: a whole-tree perspective. Ecology 99:1783-1791.

Work, T. T., D. G. McCullough, J. F. Cavey, and R. Komsa. 2005. Arrival rate of nonindigenous insect species into the United States through foreign trade. Biological Invasions 7:323-332.

Zeng, Y., V. P. Reddy, Z. Li, Y. Qin, Y. Wang, X. Pan, F. Jiang, F. Gao, and Z. Zhao. 2019. Global distribution and invasion pattern of oriental fruit fly, Bactrocera dorsalis (Diptera: Tephritidae). Journal of Applied Entomology 173:165-176.

Zhao, Z., C. Hui, R. E. Plant, M. Su, N. T. Papadopoulos, T. E. Carpenter, Z. Li, and J. R. Carey. 2019. The life table invasion models: spatial progression and species-specific partitioning. Ecology 100:e02682.

\section{SUPPORTING INFORMATION}

Additional supporting information may be found online at: http://onlinelibrary.wiley.com/doi/10.1002/eap.1991/full 